ARTICLE

\title{
Instability Analysis in Peach Bottom NPP Using a Whole Core Thermalhydraulic-Neutronic Model with RELAP5/PARCS v2.7
}

\author{
Agustín ABARCA, Teresa BARRACHINA, Rafael MIRÓ* and Gumersindo VERDÚ \\ Institute for Industrial, Radiophysical and Environmental Safety (ISIRYM) \\ Universitat Politècnica de València (UPV) \\ Cami de Vera s/n, 46021 València, Spain
}

\begin{abstract}
In this paper we present the results from a BWR stability analysis performed on an operating point, called PT_UPV, of Peach Bottom NPP. This point is inside the exclusion region and it is achieved departing from test point 3 by a control rod movement as it is usually performed in Nuclear Power Plants.

The simulation has been made with the coupled code RELAP5-MOD3.3/PARCS v2.7. The thermalhydraulic model includes all the reactor vessel components: jet pumps, recirculation pumps, downcomer, reactor core and also the separator and the dryer.

The reactor core has been modeled with 72 thermalhydraulic channels, 71 represent the active core and 1 represents the core bypass. The reactor core thermalhydraulic-to-neutronic representation (mapping) has been divided in four quadrants according to the first and second power harmonics (Lambda modes) obtained previously with the VALKIN code. This mapping was chosen in order not to condition the oscillation pattern.

The purpose of this study is to qualify this coupled code against this kind of 3D complex accidents that take place inside the core. The calculated results show that point PT_UPV is an unstable point and the obtained relative axial power distribution shows a bottom-peaked profile, which is characteristic of unstable cores.
\end{abstract}

KEYWORDS: BWR instabilities, RELAP, PARCS, Lambda modes

\section{Introduction}

To characterize the unstable behavior of the Peach Bottom Unit 2 BWR, a number of perturbation analyses were performed: arrangements with Philadelphia Electric Company (PECo) were made for conducting different series of Low Flow-Stability Tests at Peach Bottom 2, during the first quarter of 1977. ${ }^{1,2)}$ (see Table 1).

The Low Flow Stability Tests intended to measure the reactor core stability margins at the limiting conditions used in design and safety analysis, providing a one-to-one comparison to design calculations. Stability tests were conducted along the low-flow end of the rated power-flow line, and along the power-flow line corresponding to minimum recirculation pump speed.

Table 1 Peach Bottom-2 End-of-Cycle 2. Low-Flow Stability Test Conditions

\begin{tabular}{llllll}
\hline $\begin{array}{l}\text { Test } \\
\text { Number }\end{array}$ & Reactor Power & \multicolumn{2}{l}{ Core Flow Rate } & $\begin{array}{l}\text { Core } \\
\text { Pressure }\end{array}$ \\
\hline & (MWt) & $(\%$ Rated) & $(\mathrm{kg} / \mathrm{s})$ & $\begin{array}{l}(\% \\
\text { Rated })\end{array}$ & $(\mathrm{MPa})$ \\
\hline PT1 & 1995 & 60.6 & 6753.6 & 51.3 & 6.89 \\
PT2 & 1702 & 51.7 & 5657.4 & 42.0 & 6.84 \\
PT3 & 1948 & 59.2 & 5216.4 & 38.0 & 6.93 \\
PT4 & 1434 & 43.5 & 5203.8 & 38.0 & 6.89 \\
\hline
\end{tabular}

(a) Based on process computer edit (P1), corrected for steam separator pressure drop

*Corresponding author, E-mail:rmiro@iqn.upv.es

(C) 2011 Atomic Energy Society of Japan, All Rights Reserved.
The selection of this reactor was based on the fact that it is a large BWR/4 which reaches the end of its Number 2 reload fuel cycle early in 1977, with an accumulated average core exposure of $12.7 \mathrm{GWd} / \mathrm{t}$.

In previous works, ${ }^{3)}$ the results showed that point PT3 is a nearly stable point and it is at the end of cycle, while the obtained average axial power distribution shows a non bottom-peaked profile (stable).

The aim of this work is to simulate the instabilities on a new analysis point (PT_UPV), which is inside the exclusion region of the operating power-flow map, using the coupled code RELAP5-MOD3.3/PARCS v2.7.,5) This point is achieved departing from test point 3 by the control rod movement as it is usual performed in Nuclear Power Plants. Figure 1 shows the Peach-Bottom reactor power-flow map with the different regions of operation and the points corresponding to the low-flow stability tests and the new point PT UPV.

In a first analysis of these instabilities in the PT_UPV point, the thermal-hydraulic model only included the reactor core. $^{6}$

In this work, the BWR stability analysis on the PT_UPV point is performed using a detailed thermal-hydraulic model that includes all the components of the reactor vessel: jet pumps, recirculation pumps, downcomer and also the separator and the dryer.

The paper is organized as follows: in Section II the thermal-hydraulic and neutronic models are explained. 


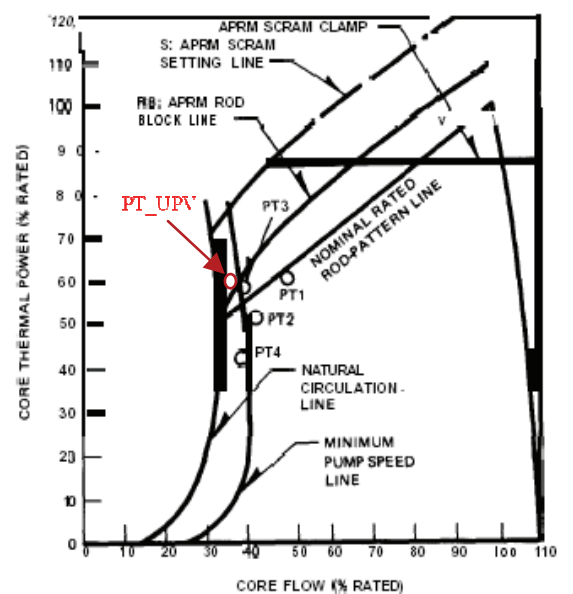

Fig. 1 Peach Bottom 2 Low Flow Stability Tests Conditions

Section III presents the results obtained. In Section IV the main conclusions of the work are summarized.

\section{Description of the Model}

The reactor core studied is composed of 648 fuel elements, being the number of fuel rods per fuel element equal to 64 with 1 instrumentation tube.

The simulation has been performed with the coupled codes RELAP5-MOD3.3/PARCSv2.7. These codes are coupled via the Parallel Virtual Machine (PVM) communication interface. RELAP5 transfers to the neutronic code the fuel temperature and the moderator density of each one of the core nodes and PARCS sends to RELAP5 the power of each node. The mapping between the thermalhydraulic and neutronic nodes is defined in an external file.

\section{Thermal-Hydraulic Model}

The thermal-hydraulic model of Peach Bottom vessel components, coolant and steam loop has been developed by means of RELAP5/MOD3.3 code. The nodalization, in SNAP format, is shown in Fig. 2.

The steam passes through four Main Steam Lines (MSLs) to the turbine and to the condenser through the bypass line. The four MSLs are modeled as only one. The Safety Relief Valves (SRVs) that discharged the steam to the suppression pool in case that the reactor pressure increases, are modeled in the steam line.

The turbine and the bypass boundary conditions at the end of the main steam line are modeled using time dependent volumes. In each one of these two steam end lines there is one valve which is maneuvered by an associated control.

There are two recirculation loops, each one has a recirculation pump which drives one jet pump (equivalent to ten real ones).

The reactor core has been modeled with the purpose that the oscillation pattern could not be affected. To achieve that, the reactor core thermal-hydraulic to neutronic representation (mapping) has been divided in four quadrants according to the first and second power harmonics (Lambda modes) obtained previously with the VALKIN code. ${ }^{7)}$ Figures 3 to 8

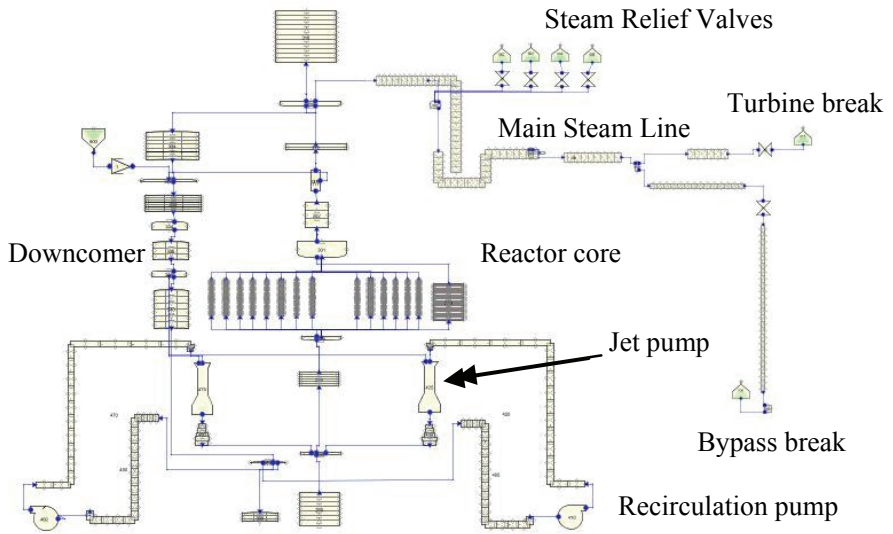

Fig. 2 SNAP representation of the thermal-hydraulic model

show the first three Lambda modes calculated with VALKIN code.

Taking into account the Lambda modes and the fuel types map, the resulting thermal-hydraulic map has 72 channels (modeled with PIPE components), 71 representing the core and 1 representing the bypass. The thermalhydraulic channel map is shown in Fig. 9. The channel numbering begins in 100. Number 250 indicates the bypass core region. In this figure, it is also marked with bold line the four quadrants defined by the first dominant Lambda modes.

The fuel design characteristics have been taken from the Ref. 8).

The core is axially subdivided into 26 nodes. The first and the last axial nodes represent the bottom and the top reflectors respectively.

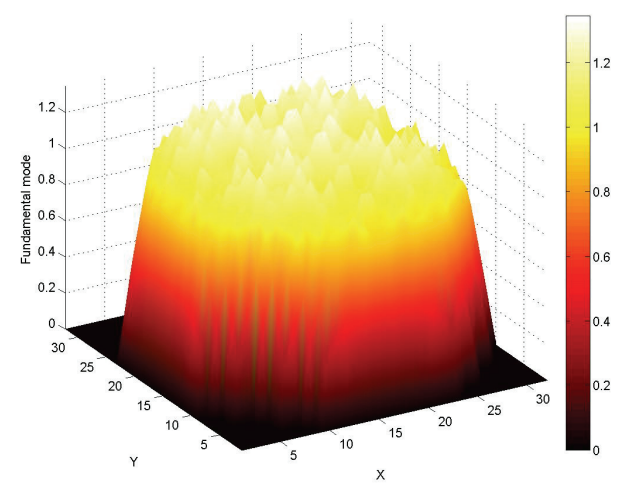

Fig. 3 3D representation of the fundamental mode

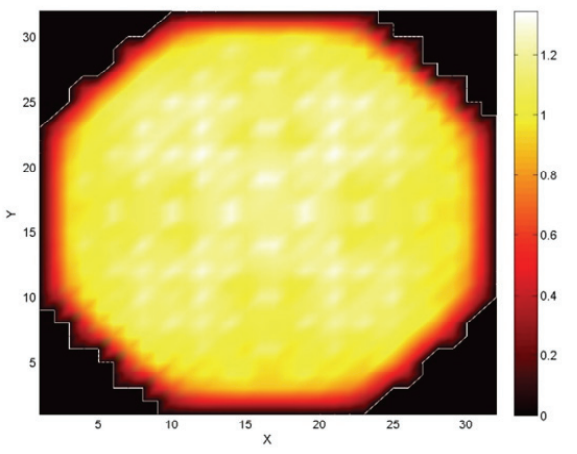

Fig. 4 3D representation of the fundamental mode 


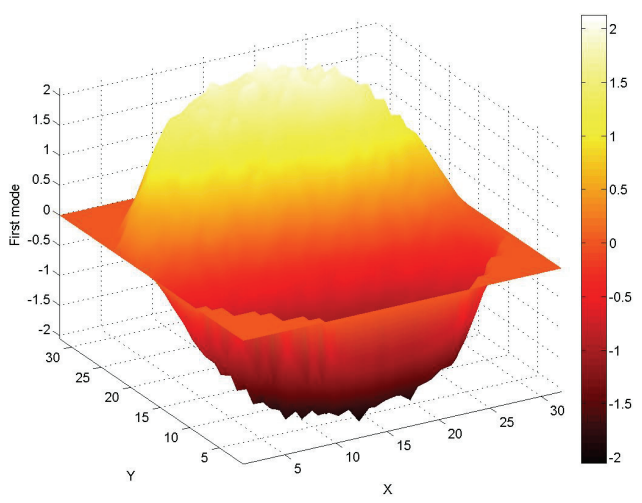

Fig. 5 3D representation of the first mode

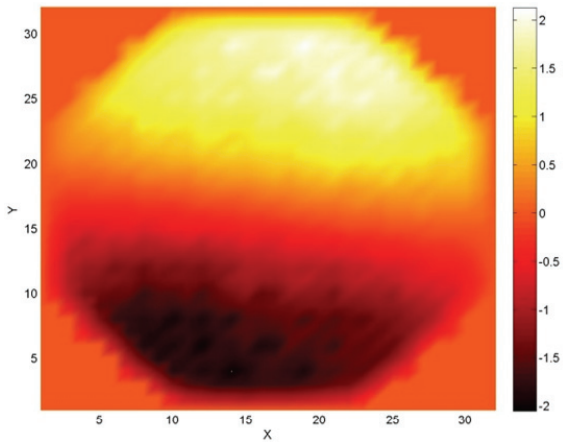

Fig. 63 D representation of the first mode

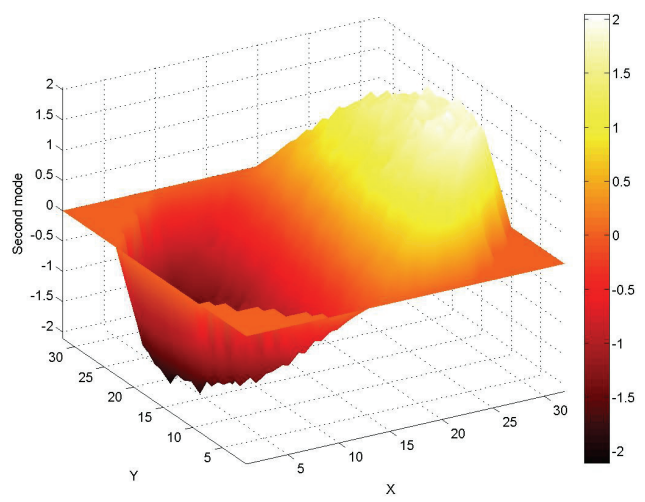

Fig. 7 3D representation of the second mode

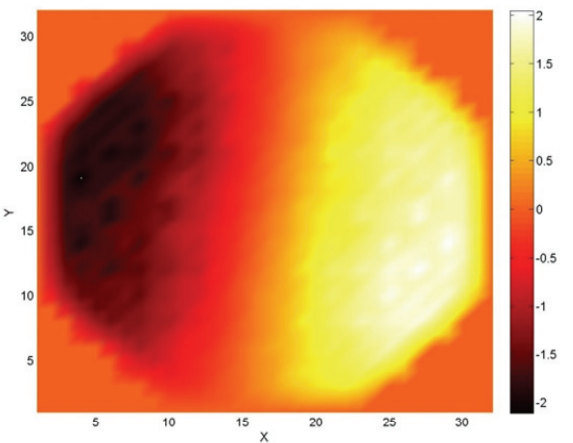

Fig. 8 Planar representation of the second mode

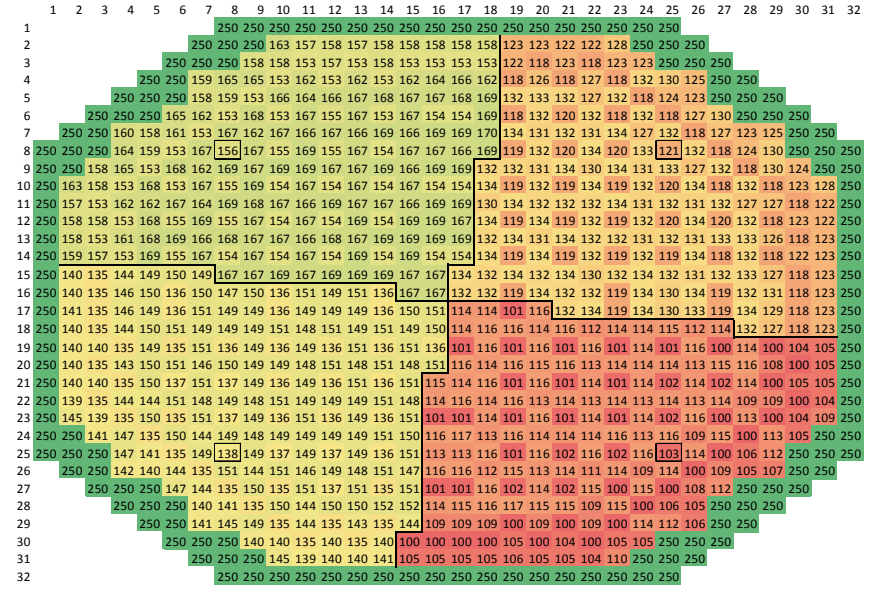

Fig. 9 Thermal-hydraulic channels

The vessel has been modeled with three zones: the lower plenum, the upper plenum and the downcomer. The thermal-hydraulic model also includes the separator component. The condensed water from the separator goes back to the core through the downcomer and jet pumps.

The feedwater flow is injected in the downcomer in a constant flow and it is modeled with a time dependent volume.

\section{Neutronic Model}

For the neutronic code, a nodalization with a $3 \mathrm{D}$ core mesh composed with 764 radial nodes has been modeled. A large set of cross section data including 435 compositions has been adopted in neutronic input deck.

The Xenon conditions considered in the simulation are the given 3D conditions from SIMULATE-3 code. ${ }^{9}$

The solution method used in PARCS v2.7 code has been the HYBRID method. This method is a hybrid ANM/NEM method. In RELAP5 the system model is solved numerically using a semi-implicit finite-difference technique.

\section{Simulation Results}

Departing from test point 3, the PT_UPV point is achieved by the control rod movement shown in Fig. 10.

The control rods movement lasts 5 seconds; at the end of the movement the majority of the banks are completely withdrawn. In Fig. 10 the first picture shows the initial position of the seven control rods banks. The movement is coded with different colors and numbers defined in the legend. Bank 1, 2 and 3 remains at its initial position while the others are withdrawn to the position 42 (number 2 in Fig. 10). Position 48 means fully withdrawn while position 0 means fully inserted.

We have decided to last $50 \mathrm{~s}$ of null transient before the control rods start moving, so that, the control rod movement starts at $50 \mathrm{~s}$ and ends at $55 \mathrm{~s}$.

At point PT_UPV, the core mass flow is equal to $4660.1 \mathrm{~kg} / \mathrm{s}(34 \%$ of the core rated mass flow) and the total reactor power is $1997.8 \mathrm{MW}(60.7 \%$ of the core rated reactor power). 

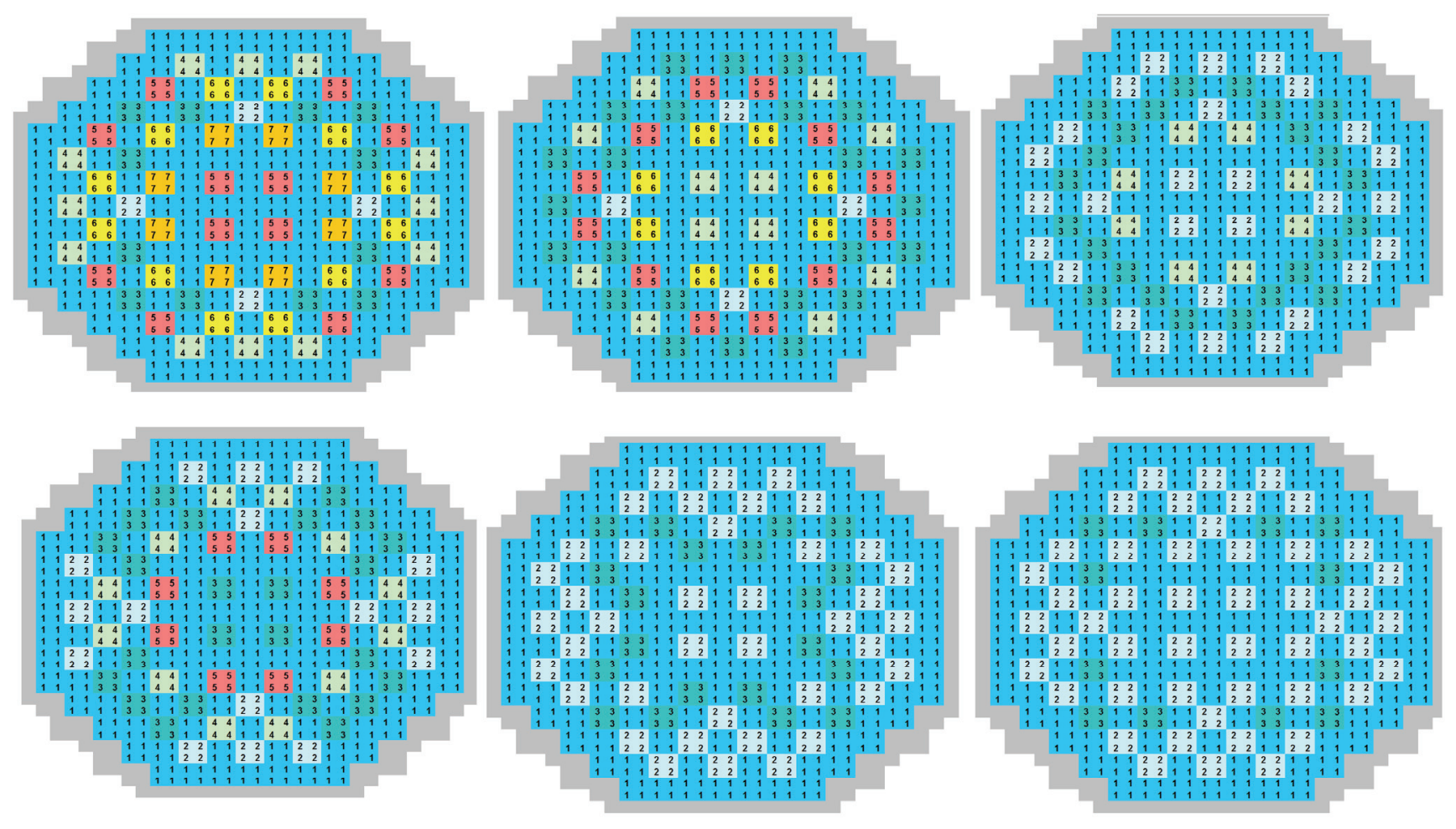

$\begin{array}{lllllll}48 & 42 & 40 & 36 & 32 & 30 & 24\end{array}$

Fig. 10 Control rods movement

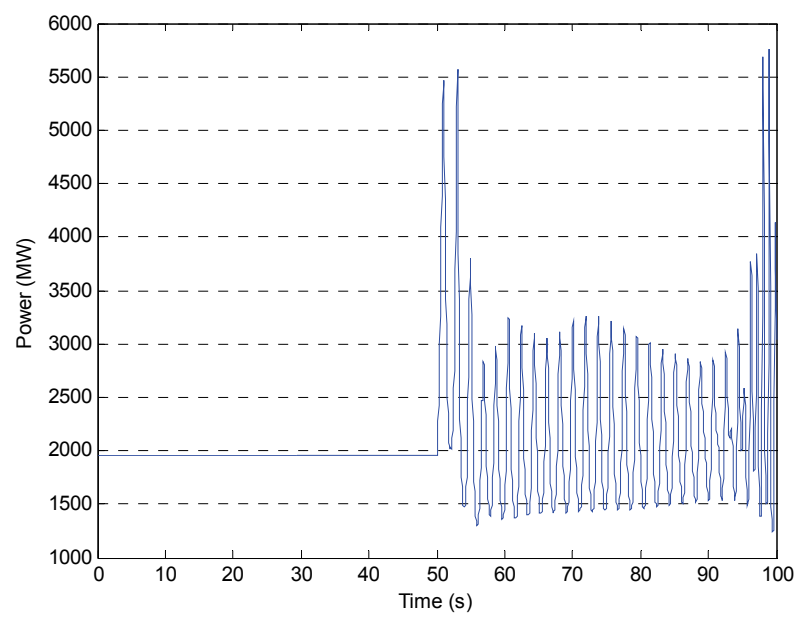

Fig. 11 Power evolution

Figure 11 shows the power evolution during the transient. The power oscillation starts at $55 \mathrm{~s}$ approximately. From $90 \mathrm{~s}$ on, the power evolution is very chaotic because of such an extremely thermal-hydraulic conditions (fuel temperature and moderator density) are not considered in the cross-sections tables used in the calculation, that is, these thermal-hydraulic values are out of the interval used to obtain the cross-section tables. The cross-section tables used in this simulation comes from Ref. 8) and these are the same sets used in the previous simulations of instability analysis at point PT3.

Figure 12 shows the power evolution in this period from $55 \mathrm{~s}$ to $90 \mathrm{~s}$.

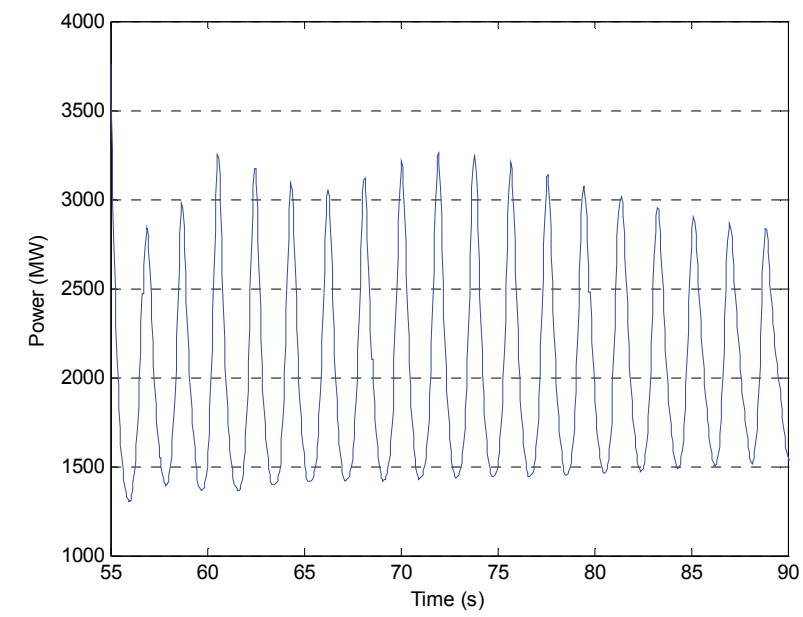

Fig. 12 Power evolution from $55 \mathrm{~s}$ to $90 \mathrm{~s}$

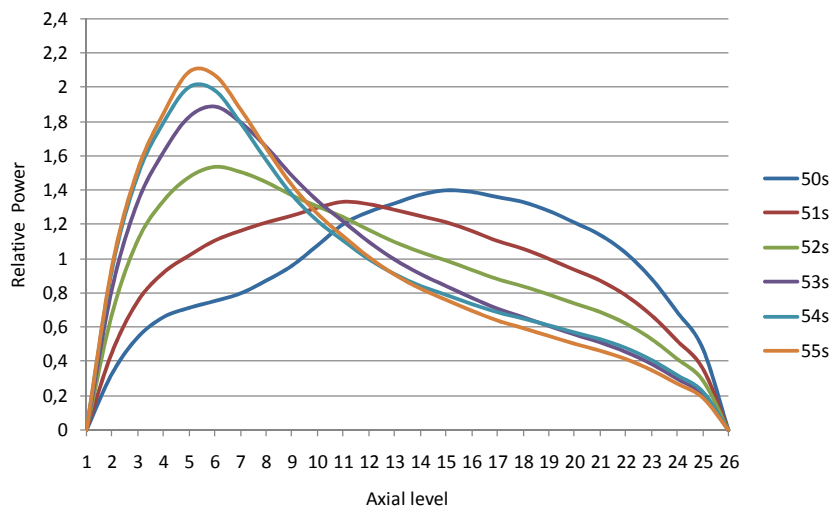

Fig. 13 Axial relative power profile evolution 

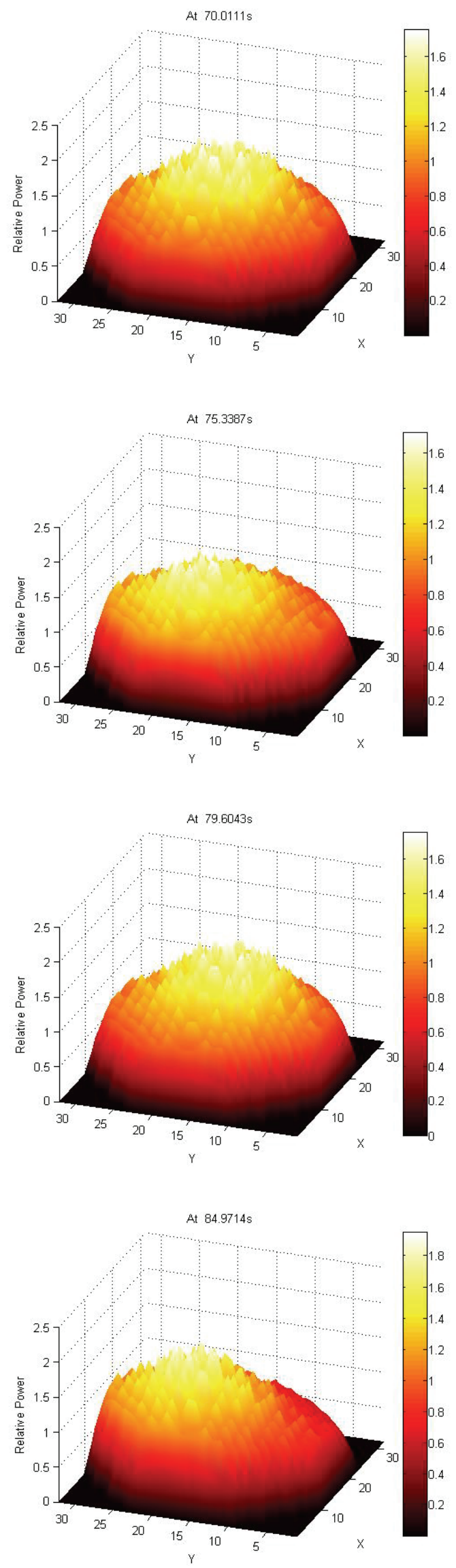

Fig. $143 \mathrm{D}$ representation of power at different simulation times

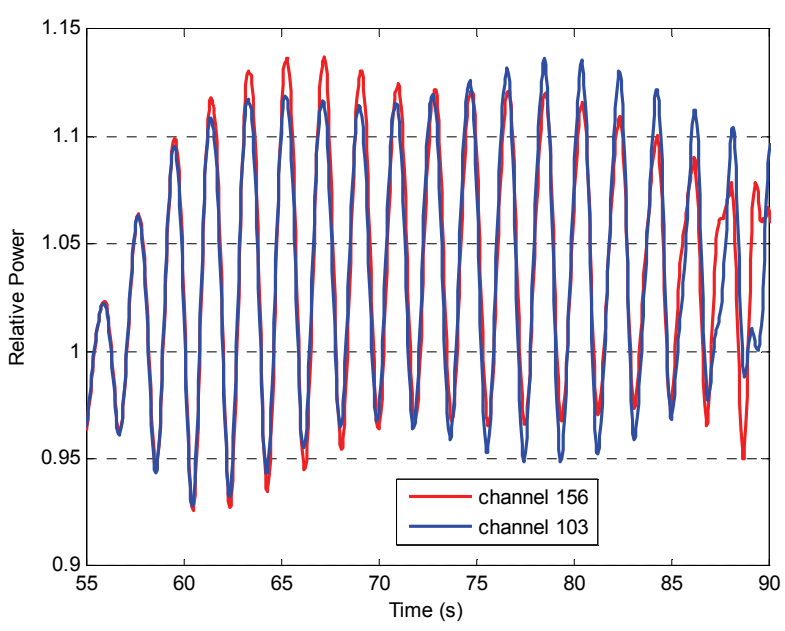

Fig. 15 Comparison of power evolution in channels 156 and 103

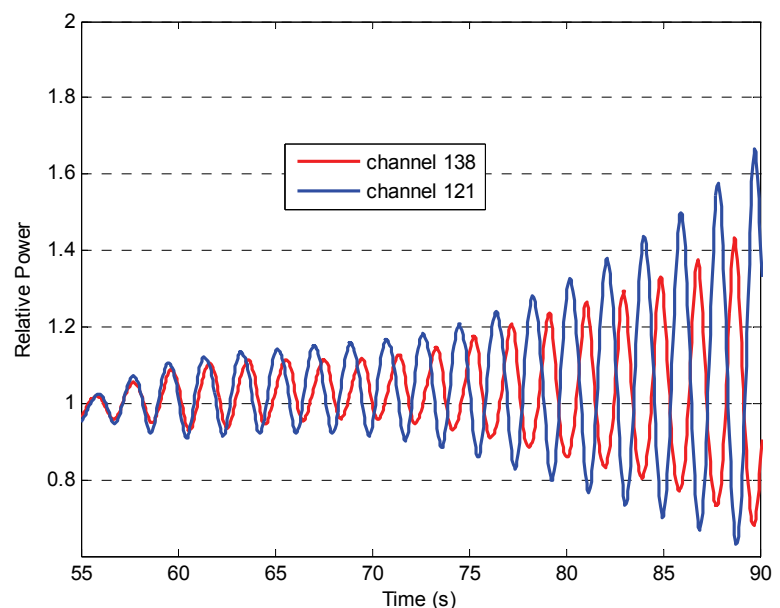

Fig. 16 Comparison of power evolution in channels 138 and 121

During the control rod movement the axial power profile becomes a bottom peak power profile as it is shown in Fig. 13.

The bottom peak power profile is characteristic of unstable cores.

Figure 14 shows the three-dimensional representation of the power in different steps of the transient.

In order to analyze the oscillation, the evolution of the inlet and outlet pressure is studied. We have analyzed four channels, each one belonging to each quadrant of the reactor core. The position of each channel in the radial thermal-hydraulic map is shown in Fig. 9: channels 156, 138, 121 and 103.

The power in these symmetrical regions is shown in Figs. 15 and 16.

The inlet and outlet mass flow in these symmetrical regions are shown in Figs. 17 to 28. 


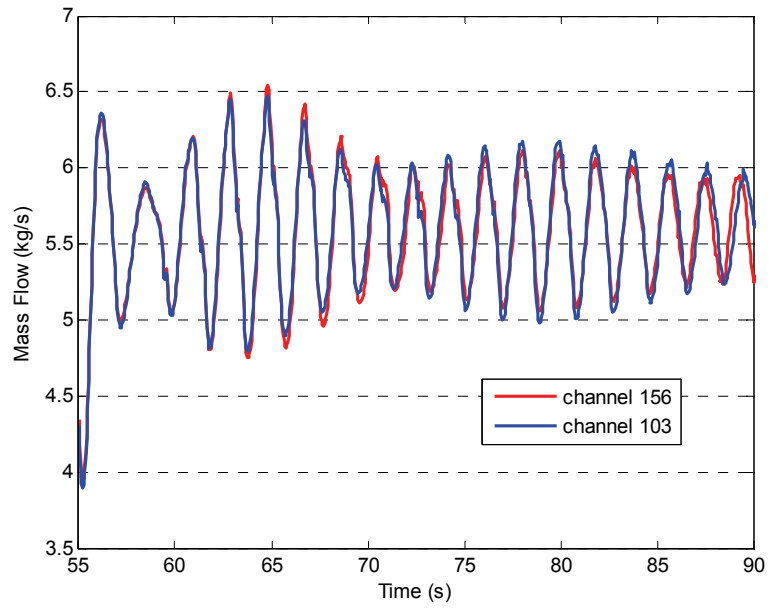

Fig. 17 Comparison of inlet mass flow evolution in channels 156 and 103

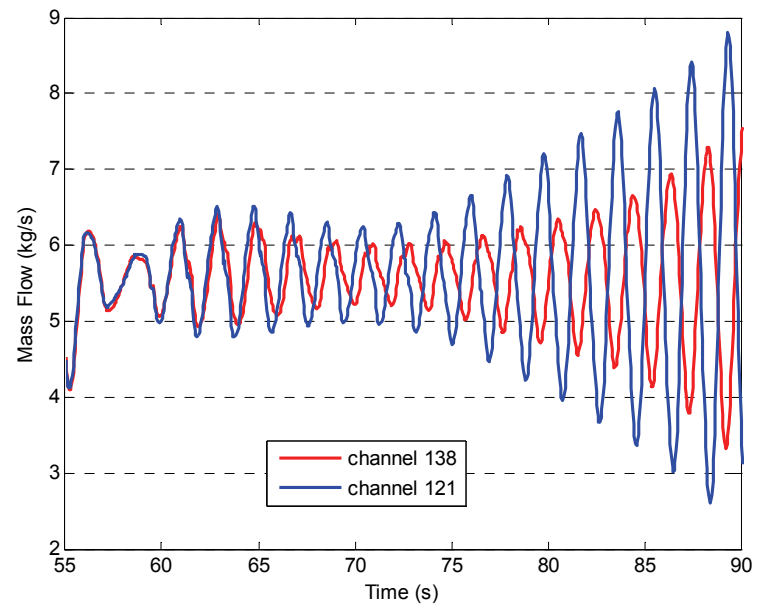

Fig. 18 Comparison of inlet mass flow evolution in channels 138 and 121

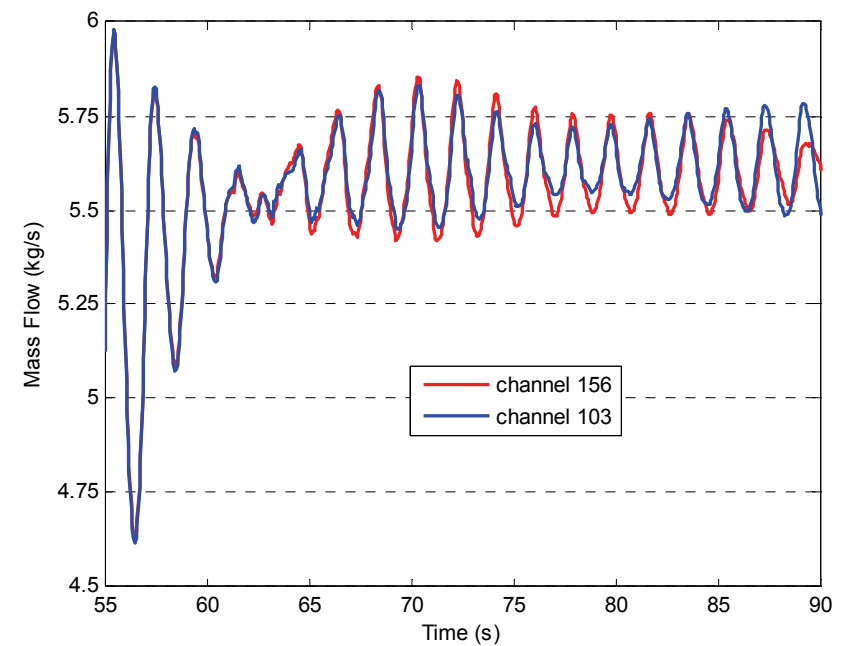

Fig. 19 Comparison of outlet mass flow evolution in channels 156 and 103

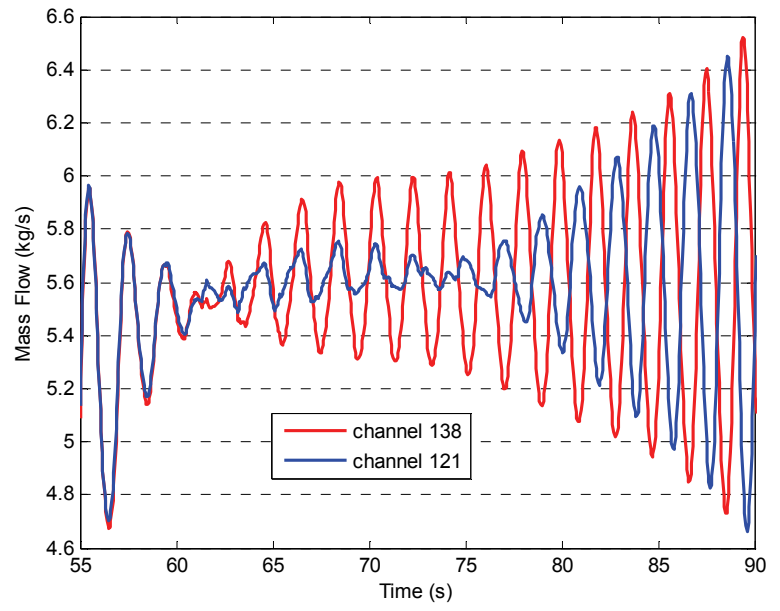

Fig. 20 Comparison of outlet mass flow evolution in channels 138 and 121

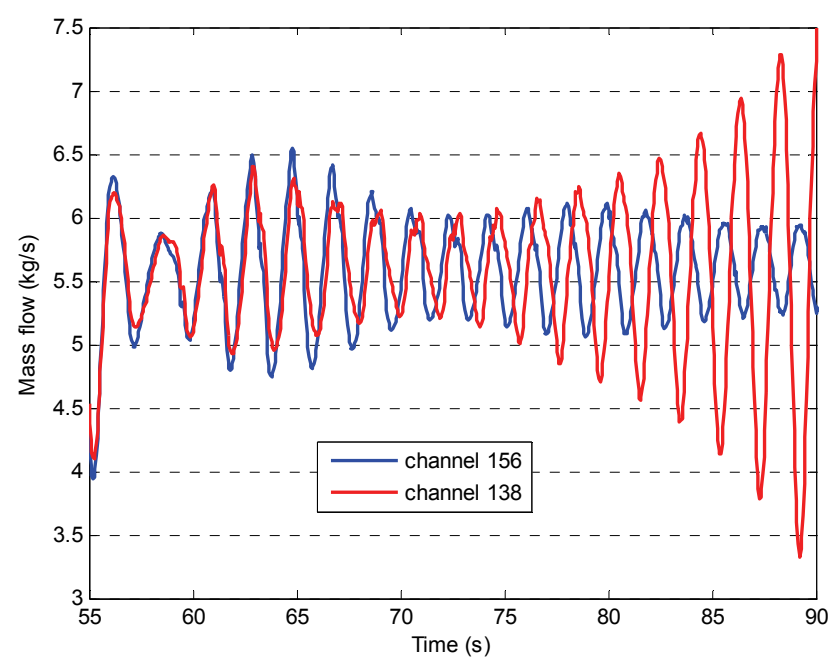

Fig. 21 Comparison of intlet mass flow evolution in channels 156 and 138

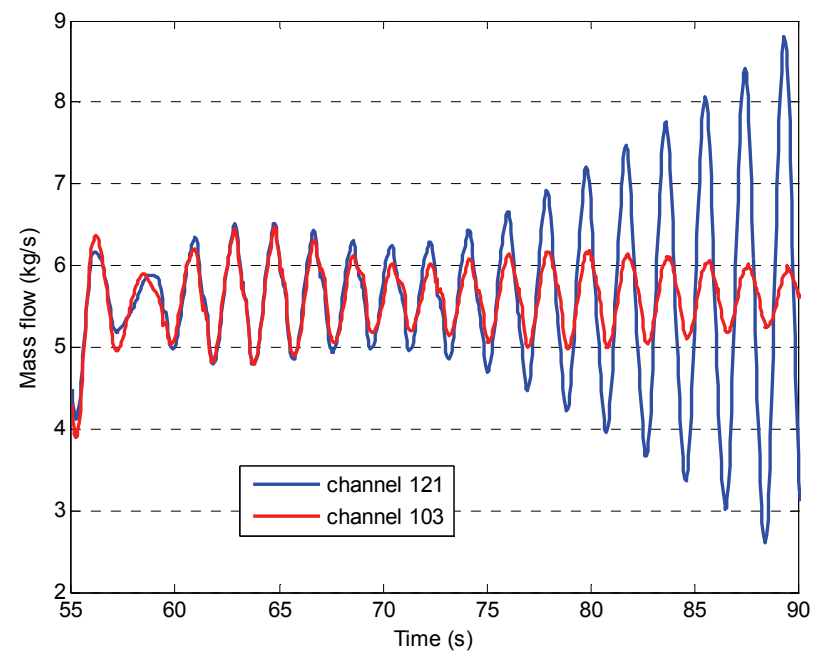

Fig. 22 Comparison of intlet mass flow evolution in channels 121 and 103 


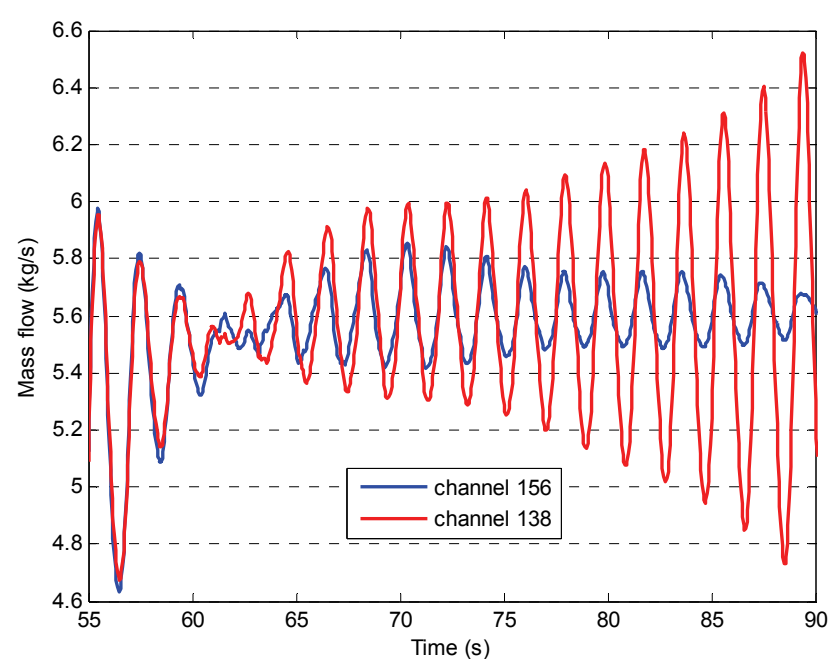

Fig. 23 Comparison of outlet mass flow evolution in channels 156 and 138

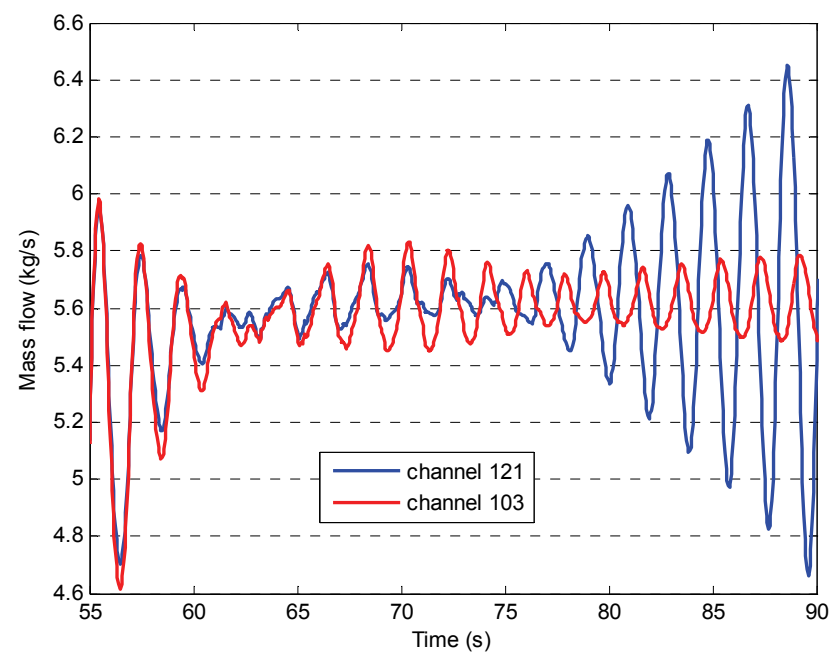

Fig. 24 Comparison of outlet mass flow evolution in channels 121 and 103

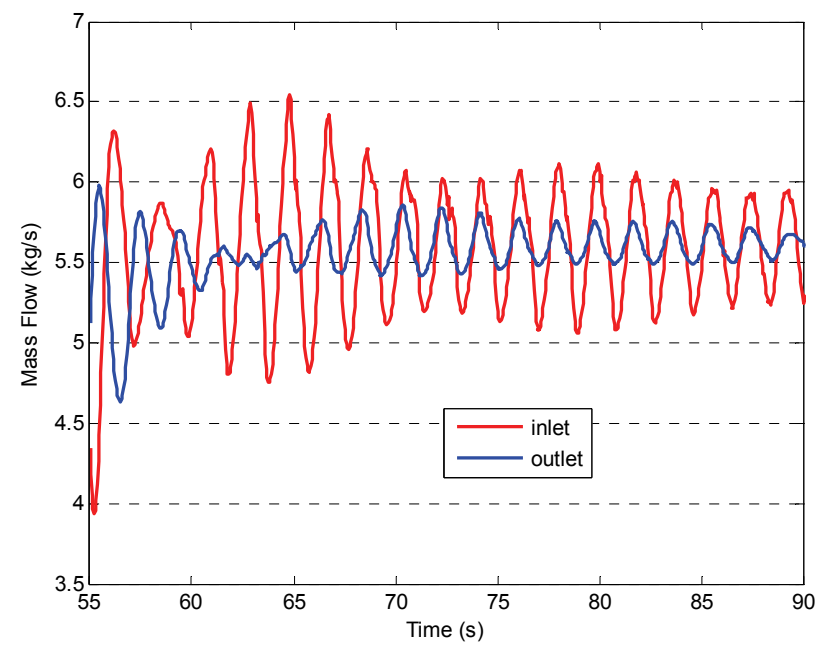

Fig. 25 Comparison of inlet and outlet mass flow evolution in channel 156

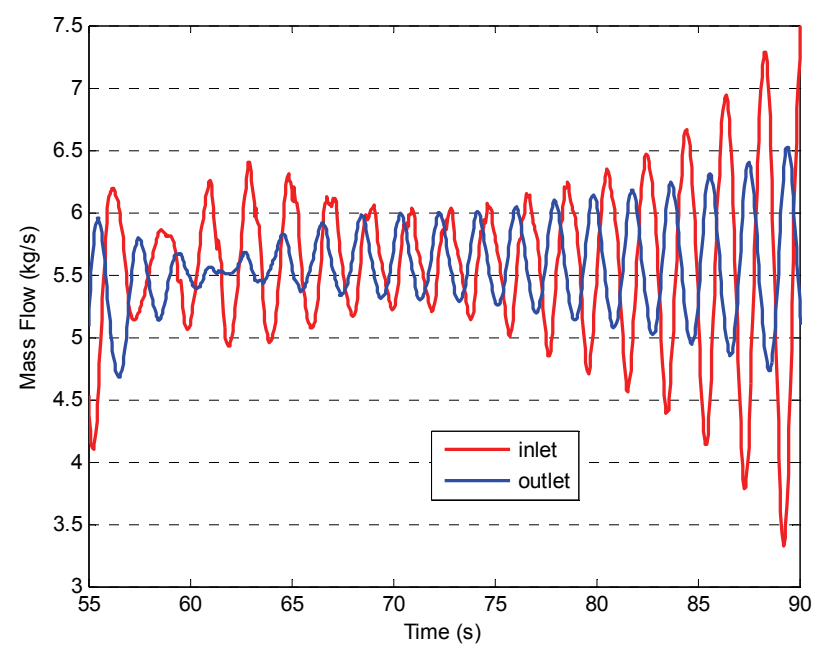

Fig. 26 Comparison of inlet and outlet mass flow evolution in channel 138

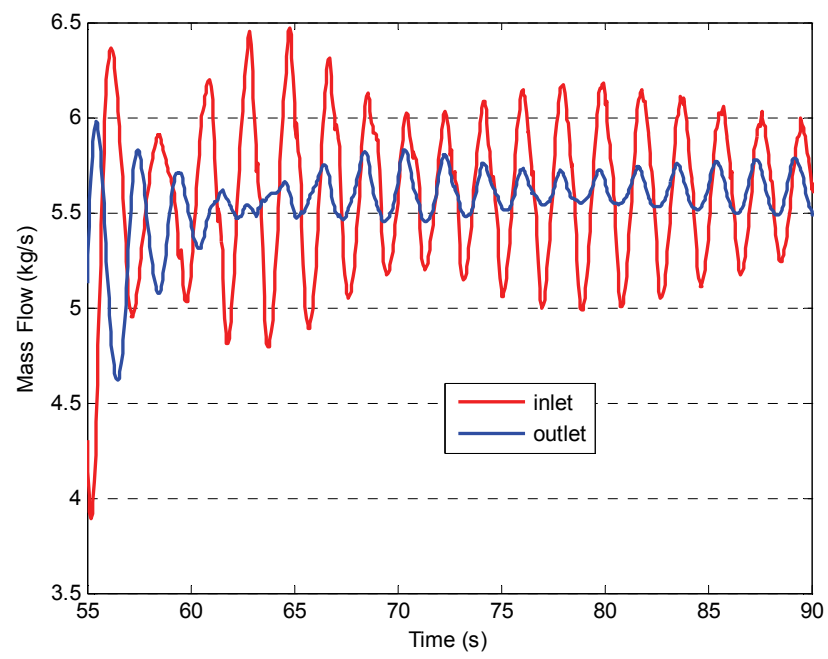

Fig. 27 Comparison of inlet and outlet mass flow evolution in channel 103

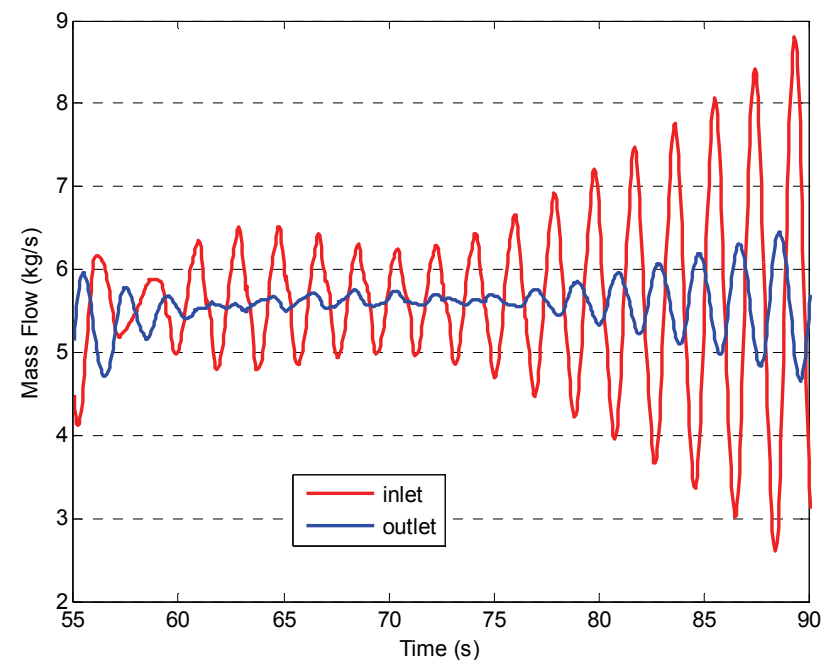

Fig. 28 Comparison of inlet and outlet mass flow evolution in channel 121 


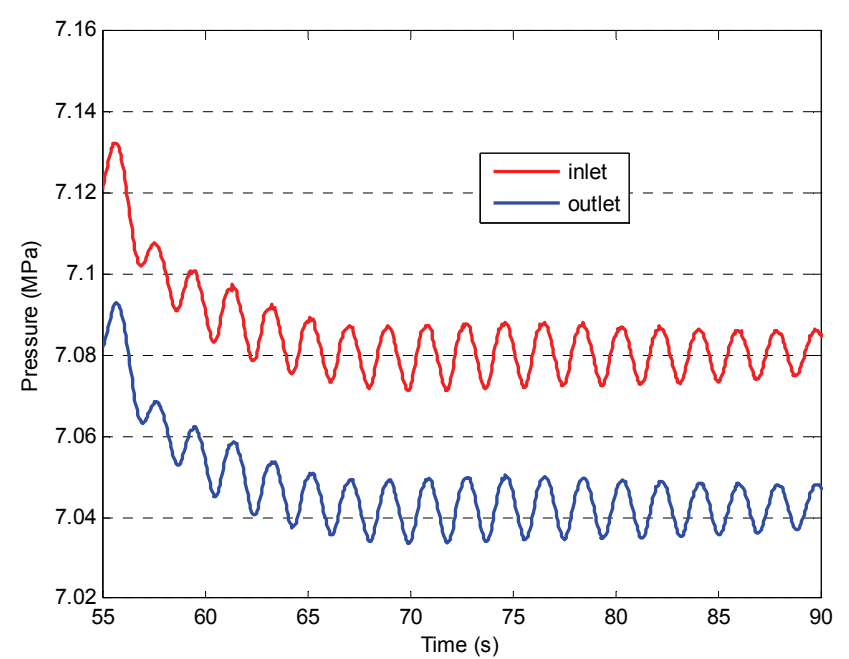

Fig. 29 Comparison of core inlet and outlet pressure time evolution

Channel 156

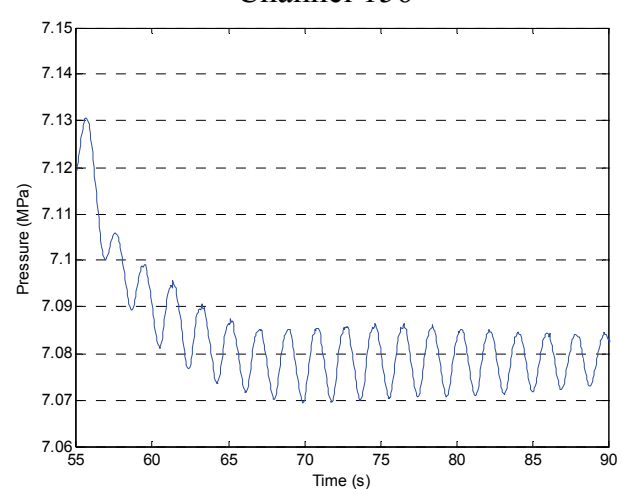

Channel 138

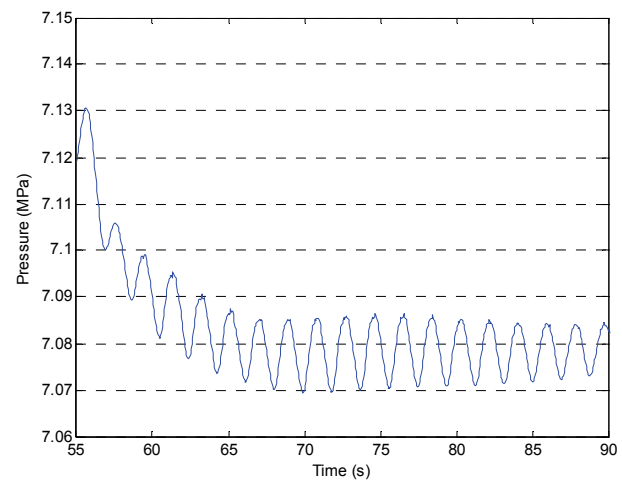

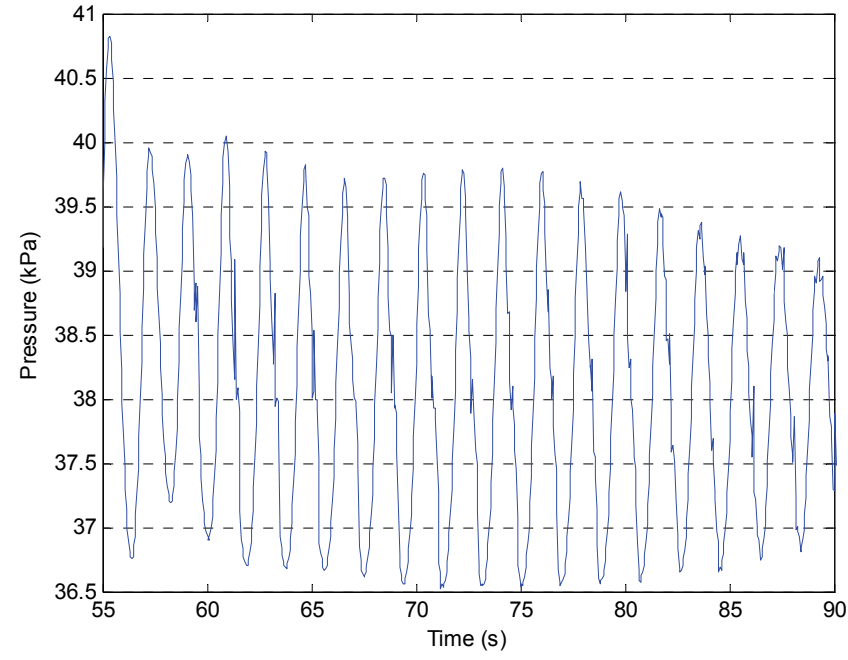

Fig. 30 Core pressure drop time evolution

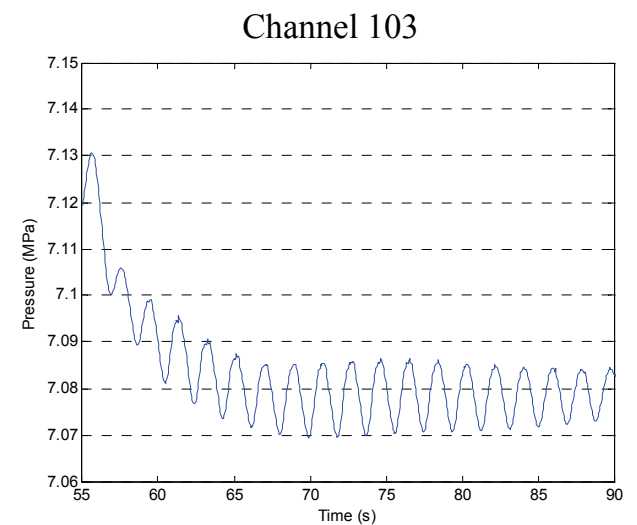

Channel 121

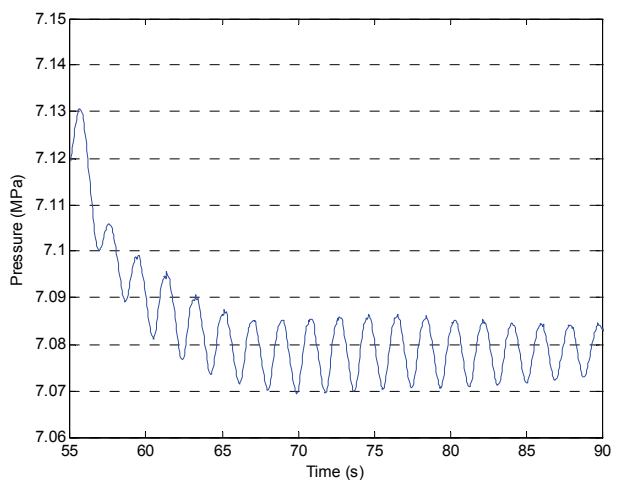

Fig. 31 Inlet pressure evolution in symmetrical channels

From Figs. 15 and 16, it can be observed that channels 156 and 103 oscillate in-phase, while channels 138 and 121 oscillate out-of-phase.

The same conclusion is achieved by comparing the inlet and the outlet mass flow between these channels.

The inlet and the outlet mass flow evolution between channels 156 and 138 are compared in Figs. 21 and 23 respectively. An out-of-phase oscillation appears between these channels. The comparison between channels 121 and 103 also shows (Figs. 22 and 24) an out-of-phase oscillation.
In order to perform a complete analysis of the instabilities, the core inlet and outlet pressure evolution during the transient is shown in Fig. 29 and the core pressure drop is shown in Fig. 30.

The pressure at the inlet and outlet in symmetrical channels are also shown in Figs. 31 and $\mathbf{3 2}$ respectively.

As it can be observed, the pressure at the inlet and at the exit of the reactor core oscillates in-phase. Therefore the pressure drop remains practically constant. This behavior is characteristic of out-of-phase oscillations. 


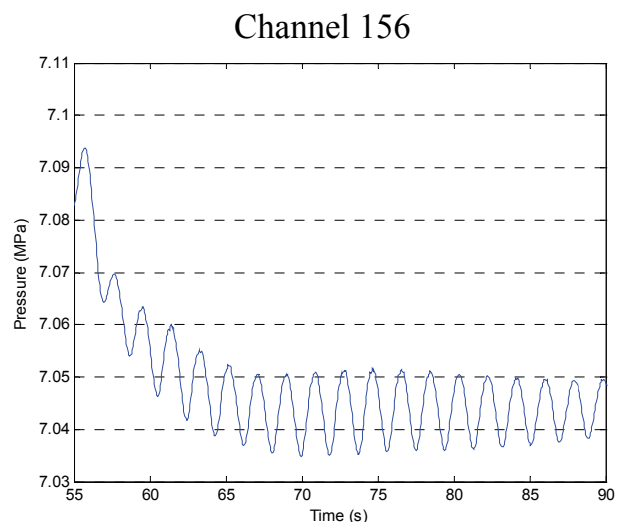

Channel 138

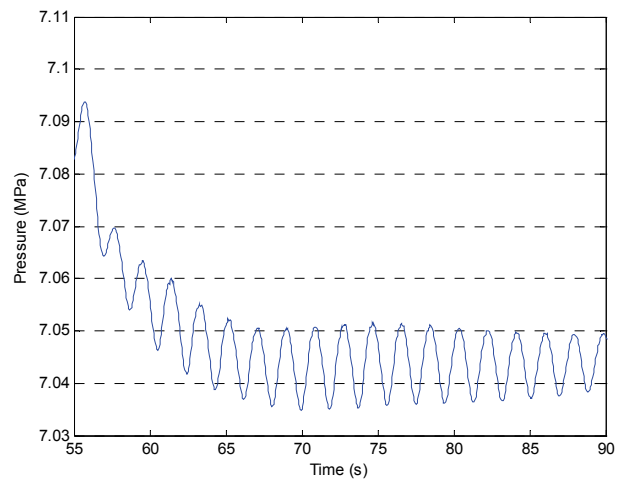

Channel 103

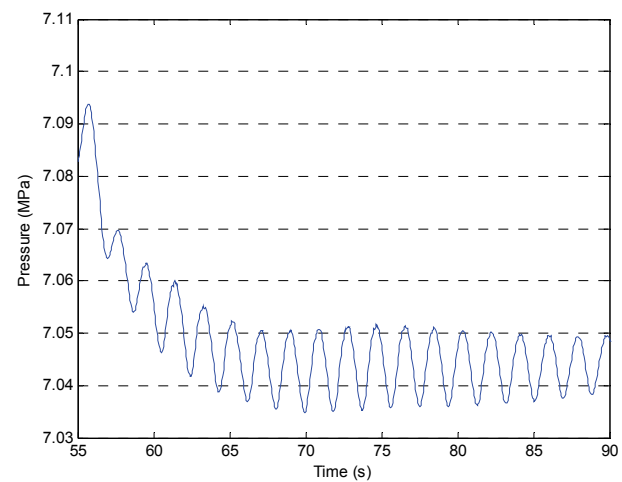

Channel 121

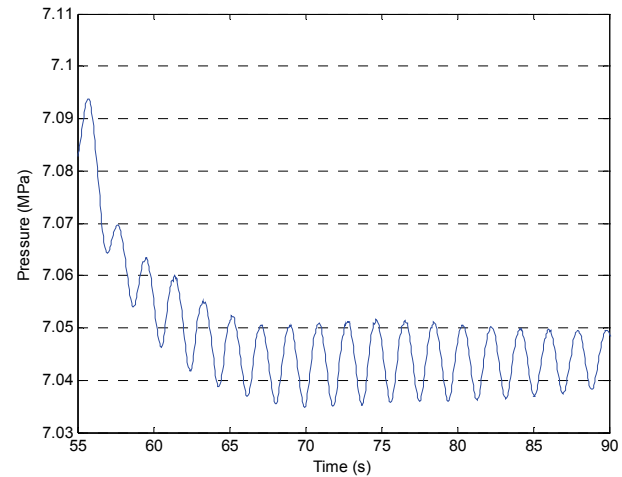

Fig. 32 Outlet pressure evolution in symmetrical channels

\section{Conclusion}

We have developed a RELAP5-MOD3.3/PARCSv2.7 model to characterize in-phase and out-of-phase oscillations in BWR NPP.

The thermal-hydraulic model used is a detailed model that includes all the components of the vessel: lower and upper plenum, recirculation pumps, downcomer, steam line and separator.

The thermal-hydraulic to neutronic mapping is based on the spatial shape of the Lambda modes obtained with VALKIN code, developed in UPV.

To check this model, the stability analysis has been performed in a new operating point PT_UPV. The calculated results show that point PT_UPV is an unstable point and the obtained relative axial power distribution shows a bottom-peaked profile, which is characteristic of unstable cores.

The results obtained show that after the control rod movement an in-phase coupled with an out-of-phase oscillation appears.

Further works will analyze the simulated LPRMs signals obtained from the neutronic code to complete the stability analyses.

\section{References}

1) L. A. Carmichael, R. O. Niemi, Transient and Stability Tests at Peach Bottom Atomic Power Station Unit 2 at End of Cycle 2,
EPRI Report NP-564, (1978).

2) N. H. Larsen, Core Design and Operating Data for Cycles 1 and 2 of Peach Bottom 2, EPRI Report NP-563, (1978).

3) R. Miró, A. M. Sánchez, G. Verdú, F. Maggini, F. D’Auria, D. Ginestar, "Peach Bottom-2 Low-Flow Stability Test using TRAC-BF1/VALKIN and RELAP5/PARCS Codes," PHYSOR 2004, Chicago, USA (2004).

4) Information Systems Laboratories, Inc., RELAP5/MOD3.3 Code Manual, NUREG/CR-5535/Rev 1-Vol I-VIII (2001).

5) T. Downar, D. Lee, Y. Xu, T. Kozlowski, J. Staundenmier, PARCS v2.7 US NRC Core Neutronics Simulator, User Manual, Purdue University (2006).

6) T. Barrachina, R. Miró, A. Soler, G. Verdú, "Qualification of the TH-3DNK coupled code RELAP5/PARCS v2.7 against a BWR unstable point at Peach Bottom nuclear power plant," Int. Conf. on Mathematics, Computational Methods \& Reactor Physics (M\&C 2009), Saratoga Springs, New York, May 3-7 (2009), [CD-ROM].

7) R. Miró, D. Ginestar, G. Verdú, D. Hennig, “A Nodal Modal Method for the Neutron Diffusion Equation. Application to BWR Instabilities Analysis," Ann. Nuc. Energy, 29, 1171-1194 (2002).

8) J. Solis et al., Boiling Water Reactor Turbine Trip (TT) Benchmark, Volume 1: Final Specifications, NEA/NSC/DOC(2001)1, (2001).

9) J. T. Cronin, K. S. Smith, D. M. Ver Planck, SIMULATE-3. Advanced three-dimensional two-group reactor analysis code, Studsvik/SOA-95/18 (1995). 